\title{
HUBUNGAN KUALITAS HIDUP LANSIA DENGAN FOOD SATISFACTION DI PTSW INA KAKA PROVINSI MALUKU
}

\author{
Anthoneta Juneth Manuhutu*, Desi, Theresia Pratiwi Elingsetyo Sanubari
}

Prodi Ilmu Keperawatan, Fakultas Kedokteran dan Ilmu Kesehatan, Universitas Kristen Satya Wacana

*Email :462016005@student.uksw.edu

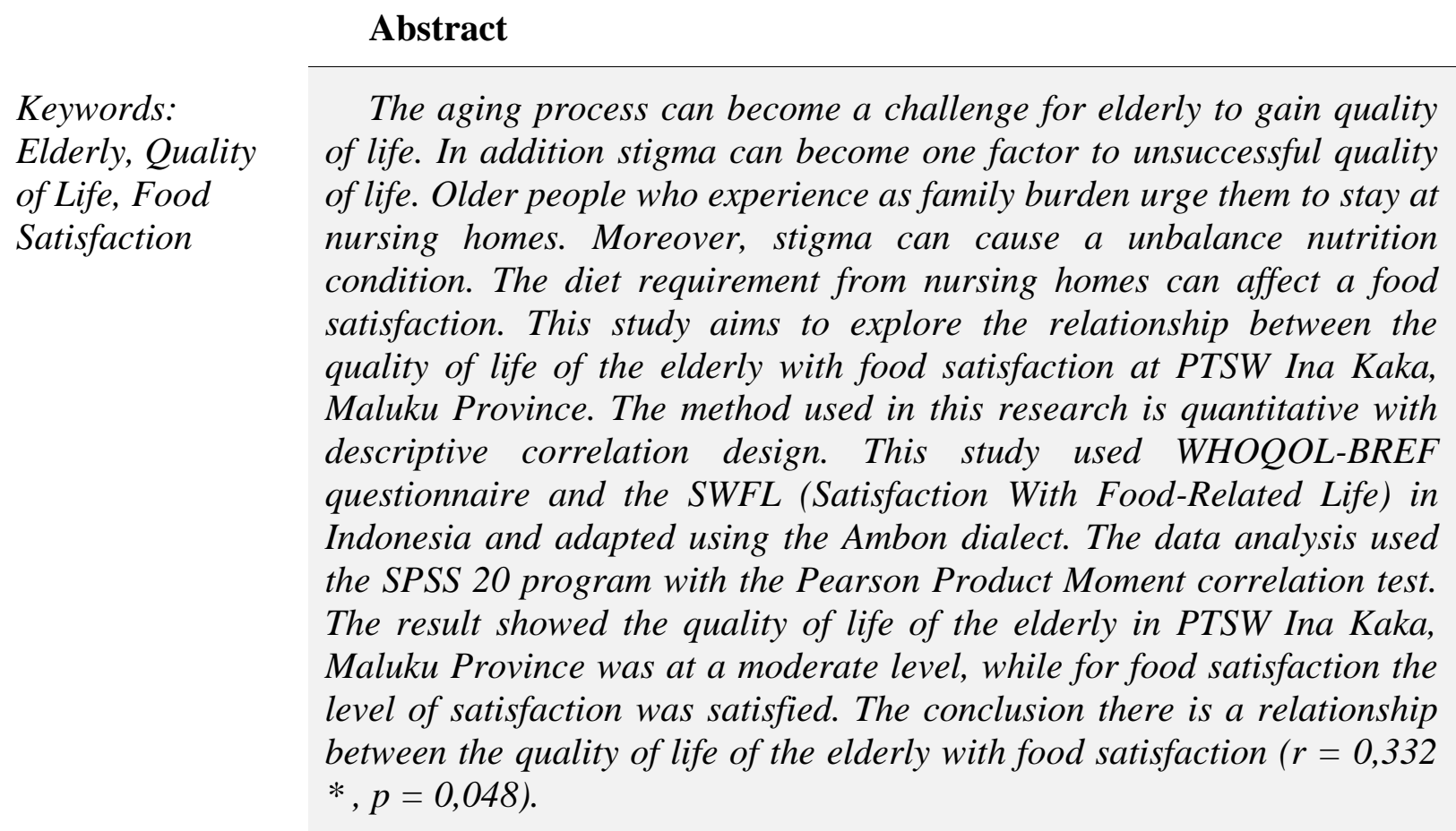

\section{PENDAHULUAN}

Secara global lansia mengalami peningkatan jumlah setiap tahunnya dan keadaan ini terjadi juga di Indonesia. Pada umumnya lansia tinggal bersama dengan keluarga namun ada pula lansia yang tinggal di panti werdha atau panti jompo. Idealnya, berada dekat keluarga adalah tempat terbaik untuk menghabiskan masa tua, mengingat keluarga merupakan pemberi dukungan yang paling potensial terhadap kelangsungan hidup mereka (Statistika Penduduk Lanjut usia, 2019). Namun ada pula lansia yang tinggal di panti dengan berbagai alasan antara lain keluarga yang tidak lagi mampu merawatnya, tidak lagi memiliki anggota keluarga dan tidak sedikit lansia yang memilih tinggal karena keinginan pribadi. Meningkatnya jumlah lansia di Indonesia mendorong perlunya peningkatan kualitas hidup. Menurut Risdianto (2009) bahwa kesejahteraan menjadi salah satu parameter tingginya kualitas hidup lanjut usia sehingga lansia dapat menikmati kehidupan masa tuanya. Kualitas hidup menurut World Health Organization Quality of Life (WHOQOL) didefinisikan sebagai persepsi individu terhadap kehidupannya di masyarakat dalam konteks budaya dan sistem nilai yang ada yang terkait dengan tujuan, harapan, standar, dan perhatian (Yulianti, 2014). Gureje (2008) menekankan mengenai pentingnya harapan hidup dan kualitas hidup bagi lansia. Ada empat domain yang penting untuk mengetahui kualitas hidup individu. Domain-domain tersebut berdasarkan Azizah (2016) antara lain domain fisik, psikologis, sosial, dan lingkungan. 
Menjadi tua merupakan sebuah proses yang tak terelakkan namun pencapaian kualitas hidup lansia masih menjadi tantangan. Hal tersebut dikarenakan seiring bertambahnya usia maka akan terjadi perubahan pada lansia meliputi penurunan kondisi fisik, perubahan psikologis yang dipengaruhi oleh menurunnya kondisi fisik, perubahan psikologis (Nugroho, 2008). Perubahan lainnya menurut Noorkasiani (2009) yaitu penurunan fungsi biologis, psikologis, sosial dan ekonomi. Salah satu faktor yang mengakibatkan tidak tercapainya kualitas hidup pada lansia adalah adanya stigma. Masyarakat cenderung menganggap bahwa lansia yang tinggal bersama keluarga sebagai orang tidak berguna, bahkan hanya sebagai beban keluarga. Anggapan ini memicu lansia memilih diam dan menerima keadaan (Rosita, 2012). Stigma tersebut dapat berdampak bagi keluarga lansia dan lansia itu sendiri. Bagi keluarga lansia yang memiliki keterbatasan dari segi ekonomi dan merasa tidak mampu merawat lansia maka lansia akan di masukkan ke panti. Bagi lansia stigma sebagai beban keluarga mendorong mereka untuk tinggal di panti werdha.

Di sisi lain, stigma juga bisa berpengaruh pada pemenuhan gizi lansia. Menurut Amarantos (2001) bahwa rasa, kenikmatan dari makanan, dan pengalaman saat makan adalah hal yang penting dalam mengevaluasi kualitas hidup lansia. Pada lansia yang tinggal di panti werdha, makanan yang dikonsumsi dimasak oleh pengurus panti yang disesuaikan dengan selera pengurus yang memasak. Pemenuhan sepihak yang dilakukan oleh pihak panti werdha dapat berdampak pada kepuasan makan lansia. Tingkat kepuasan makanan (food satisfaction) yang tidak terpenuhi akan menimbulkan risiko pada lansia, yaitu masalah psikologis lansia. Dilaporkan bahwa lansia yang menderita malnutrisi mengalami peningkatan morbiditas, mortalitas dan menurunkan kualitas hidup (Aliabadi, 2008). Penelitian ini bertujuan untuk mengeksplorasi hubungan antara kualitas hidup lansia dengan food satisfaction di PTSW Ina Kaka Provinsi Maluku.

\section{METODE}

Metode yang digunakan dalam penelitian ini adalah kuantitatif dengan desain deskriptif correlation. Penelitian ini dilakukan di PTSW Ina Kaka Provinsi Maluku pada bulan Juli sampai Agustus 2020. Riset partisipan penelitian ditentukan menggunakan teknik purposive sampling dengan kriteria berusia 60 tahun ke atas, bisa membaca dan menulis, dapat berkomunikasi dengan baik serta bersedia menjadi partisipan. Berdasarkan kriteria maka responden yang didapat sejumlah 36 orang dari total 45 orang lansia. Instrument yang digunakan dalam penelitian ini adalah kuesioner WHOQOLBREF dan kuesioner SWFL (Satisfaction With Food-Related Life) yang diterjemahkan ke Bahasa Indonesia serta diadaptasikan menggunakan dialek Ambon. Kedua kuesioner ini sudah teruji reliable dan valid. Nilai uji reliabilitas cronbarch's alpha pada kuesioner quality of life 0,911 dan nilai uji validitasnya berada pada rentang 0,367-0,799 sedangkan pada kuesioner food satisfaction 0,637 dan nilai validitasnya $0,423-0,808$. Kuesioner WHOQOL-BREF pada skor tiap dimensinya diterjemahkan ke dalam bahasa Indonesia dan setiap pertanyaan diberikan nilai 1 sampai 5 dan nilai paling tinggi merupakan kualitas hidup yang lebih baik. Skor dari tiap domain dihitung dengan mengalikan rata-rata setiap item dengan 4 . Adapun domain dalam kualitas hidup yaitu item pertanyaan kualitas hidup secara umum nomor 1 , item pertanyaan kesehatan umum nomor 2 , item pertanyaan dari domain fisik nomor 3-4, 10, 15-18 (tujuh pertanyaan), item pertanyaan dari domain psikologis nomor 5-7, 11,19,26 (enam pertanyaan), item pertanyaan dari domain hubungan sosial nomor 20-22 (tiga pertanyaan) dan item pertanyaan dari domain lingkungan nomor 89, 12-14, 23-25 (delapan pertanyaan). Sedangkan kuesioner SWFL (Satisfaction With Food-Related Life) adalah kuesioner untuk mengukur kepuasan terhadap makanan dalam kehidupan. Persetujuan pada pernyataan menggunakan skala Likert. Data yang diperoleh diolah menggunakan program SPSS 20 dengan menggunakan uji korelasi Pearson Product Moment. 


\section{HASIL}

hasil yang didapatkan melingkupi: karakteristik lansia, kualitas hidup lansia, food satisfaction lansia, hubungan kualitas hidup lansia dan food satisfaction.

\section{Karakteristik Lansia}

Tabel 1. Profil Karakteristik Lansia di PTSW Ina Kaka Provinsi Maluku

\begin{tabular}{lcc} 
Karakteristik & n & $\%$ \\
\hline Umur & & \\
- Lansia (60-70 tahun) & 17 & $47 \%$ \\
- Lansia tua (75-90 tahun) & 19 & $53 \%$ \\
\hline Jenis Kelamin & & \\
- Laki-laki & 18 & $50 \%$ \\
- Perempuan & 18 & $50 \%$ \\
\hline Agama & & \\
- Kristen Protestan & 34 & $94 \%$ \\
- Kristen Katolik & 1 & $3 \%$ \\
- Islam & 1 & $3 \%$ \\
\hline Pendidikan Terakhir & & \\
- Tidak sama sekali & 1 & $3 \%$ \\
- SD & 21 & $58 \%$ \\
- SMP & 5 & $14 \%$ \\
- SMA & 8 & $22 \%$ \\
- PT & 1 & $3 \%$ \\
\hline Status Perkawinan & & \\
- Belum Menikah & 5 & $14 \%$ \\
- Menikah & 8 & $22 \%$ \\
- Cerai Mati & 23 & $64 \%$ \\
\hline
\end{tabular}

\section{Kualitas Hidup Lansia}

Tabel 2. Kualitas Hidup Lansia di PTSW Ina Kaka Provinsi Maluku

a. Kualitas hidup secara umum

\begin{tabular}{lcc}
\hline Variabel & n & \% \\
\hline Kualitas hidup & & \\
- Sedang & 28 & $78 \%$ \\
- Tinggi & 8 & $22 \%$ \\
\hline b. Kualitas hidup per domain & \\
\hline Variabel & $\mathbf{n}$ & $\%$ \\
\hline Faktor Fisik & & \\
- Buruk & 6 & $17 \%$ \\
- Cukup & 21 & $58 \%$ \\
- Baik & 7 & $19 \%$ \\
- Sangat Baik & 2 & $6 \%$ \\
\hline Faktor Psikologis & & \\
- Buruk & 6 & $17 \%$ \\
- Cukup & 19 & $53 \%$ \\
- Baik & 11 & $30 \%$ \\
\hline Faktor & & \\
Lingkungan & 1 & $3 \%$ \\
- Buruk & 13 & $36 \%$ \\
- Cukup & 16 & $44 \%$ \\
- Baik & 6 & $17 \%$ \\
- Sangat Baik & & \\
\hline & & \\
\hline
\end{tabular}

\begin{tabular}{lcc}
\hline Faktor Sosial & & \\
- Buruk & 8 & $22 \%$ \\
- Cukup & 6 & $17 \%$ \\
- Baik & 18 & $50 \%$ \\
- Sangat Baik & 4 & $11 \%$ \\
\hline
\end{tabular}

\section{Food Satisfaction Lansia}

Tabel 3. Food Satisfaction Lansia di PTSW Ina Kaka Provinsi Maluku

\begin{tabular}{lcc} 
Variabel & $\mathbf{n}$ & $\%$ \\
\hline Food Satisfaction & & \\
- Cukup puas & 7 & $19 \%$ \\
- Puas & 29 & $81 \%$ \\
\hline
\end{tabular}

\section{Hubungan Kualitas Hidup dan Food Satisfaction}

Tabel 4. Hubungan Kualitas Hidup dan Food Satisfaction di PTSW Ina Kaka Provinsi Maluku

\begin{tabular}{|c|c|c|}
\hline Variabel & $\begin{array}{c}\text { Pengujian } \\
\text { (Analisis } \\
\text { korelasi pearson } \\
\text { product } \\
\text { moment) }\end{array}$ & $\begin{array}{l}\text { Interpretasi } \\
\text { Korelasi } \\
(\mathrm{a}=0,05)\end{array}$ \\
\hline & $\mathrm{r} \quad \mathrm{p}$ & \\
\hline $\begin{array}{l}\text { Kualitas hidup } \\
\text { dengan food } \\
\text { satisfaction }\end{array}$ & $0,332^{*}$ & Signifikan \\
\hline
\end{tabular}

\section{PEMBAHASAN}

\section{Kualitas hidup lansia di PTSW Ina Kaka Provinsi Maluku}

Kualitas hidup merupakan suatu persepsi individu yang berkaitan dengan tujuan, harapan, standar serta perhatian dalam kehidupannya di masyarakat dalam konteks budaya dan sistem nilai yang ada. Hal tersebut memberikan pengertian bahwa kualitas hidup dipengaruhi oleh hubungan lansia dengan lingkungan sekitar, kondisi fisiknya, kondisi psikososialnya serta tingkat kemandirian lansia (Suprajitno, 2019). Terdapat beberapa faktor untuk menentukan tingkat kesejahteraan seseorang yang mencerminkan kualitas hidupnya. Faktorfaktor tersebut antara lain usia, jenis kelamin, tingkat pendidikan, status pernikahan, status pekerjaan, penghasilan, dan adanya penyakit kronis pada lansia. Faktor-faktor ini adalah faktor resiko dalam menentukan kualitas hidup lansia kedepannya dikarenakan jika ada perubahan atau gangguan pada salah satu poin maka dapat menurunkan kualitas hidup lansia (Gureje, 2008). 
Rohmah (2012) berpendapat bahwa, lansia yang memiliki kondisi fisik yang baik memungkinkan lansia untuk mencapai penuaan yang berkulaitas. Pada hasil penelitian menunjukan sebagian besar lansia memiliki kekuatan fisik yang cukup. Mereka masih bisa beraktivitas setiap hari namun tidak dapat melakukan aktivitas berat. Aktivitas yang dilakukan hanya aktivitas ringan seperti merapikan tempat tidur, menyapu kamar, dan beberapa aktivitas ringan lainnya dikarenakan kebersihan wisma secara keseluruhan merupakan tugas dari penjaga tiap-tiap wisma. Hal tersebut juga dikarenakan kondisi fisik lansia sudah melemah akibat degenerasi fungsi otot tulang sehingga kekuatan menurun.

Data dilapangan menunjukan bahwa jumlah lansia perempuan dan laki-laki sama namun lansia perempuan cenderung lebih mandiri. Kemandirian yang dimaksud terkait dengan aktivitas kerumah tanggaan, salah satunya adalah memasak. Jika ada lansia yang mempunyai keinganan untuk mengonsumsi makanan di luar yang disediakan pihak panti maka dia akan melakukan inisiatif untuk memasak sendiri. Saat lansia berhasil mewujudkan hal itu maka dirinya merasa senang dan hal tersebut berdampak kepada kondisi psikologisnya.

Jika berbicara tentang psikologis, baik lansia wanita maupun laki-laki dapat dikatakan bahwa kondisi psikologisnya cukup, artinya hampir sebagian besar lansia mengatakan mereka merasa kebutuhan hidup lansia yang disediakan pihak panti sudah baik. Contohnya, penyediaan makanan bagi lansia oleh pihak panti. Makanan yang dikonsumsi lansia memberikan kepuasan baik untuk lansia perempuan maupun lakilaki. Kepuasan ini memberikan dampak baik bagi psikologis lansia. Psikologis yang baik akan berpengaruh terhadap kualitas hidup dikarenakan faktor psikologis merupakan faktor penting bagi individu untuk melakukan kontrol terhadap semua kejadian yang dialaminya dalam kehidupan. Selain faktor psikologis, faktor lain seperti sosial dan lingkungan juga memberi dampak bagi kualitas hidup lansia.

Dari segi lingkungan, lansia mengaku bahwa mereka sudah merasa puas dengan lingkungan tempat tinggal mereka sekarang. Kepuasan ini terkait dengan lingkungan panti yang tenang sehingga lansia tidak merasa terganggu. Selain itu, sebagian besar lansia merasa aman dan nyaman tinggal di panti. Kenyamanan tersebut dilihat dari segi kebersihan wisma dan fasilitas yang disediakan. Lansia yang sudah cukup lama tinggal di panti mereka sudah dapat beradaptasi dengan lingkungan panti dengan baik.

Kualitas hidup lansia terkait faktor sosial mayoritasnya masuk dalam kategori baik. Hal ini disebabkan karena interaksi antar lansia baik. Interaksi yang dibangun lansia berupa duduk bersama sambil bercerita dan makan bersama di meja makan sedangkan interaksi lansia dengan masyarakat di sekitar panti berupa saling sapa dan tidak terjadinya keributan yang ditimbulkan oleh warga sekitar panti.

\section{Food satisfaction lansia}

Makanan adalah suatu faktor penting untuk menopang keberlangsungan hidup terutama bagi lansia. Agar lansia bisa menikmati makanannya dan merasa puas perlu adanya penyediaan makanan yang sesuai untuk lansia. Lansia yang tinggal di keluarga pemenuhan kebutuhan makannya akan berbeda dengan lansia yang tinggal di panti. Di PTSW Ina Kaka Provinsi Maluku salah satu bentuk pelayanan yang disediakan yaitu terkait pelayanan makan. Lansia yang tinggal di panti akan makan empat kali sehari antara lain sarapan, makan siang, snack sore dan makan malam. Lansia akan merasa puas dengan makanannya jika rasa, tekstur, tampilan, variasi dan porsi makanan sudah sesuai. Hal ini diwujudkan karena pihak panti PTSW Ina Kaka Provinsi Maluku melibatkan ahli gizi yang akan mengatur kebutuhan makan lansia dan juga juru masak yang akan memasak makanan berupa nasi, sayur, dan lauk-pauk untuk semua lansia yang ada di panti. Setelah makanan selesai dimasak, selanjutnya makanan tersebut akan dibagikan untuk tiap-tiap wisma dan lansia akan mengambil makanan sesuai porsinya masingmasing dan hal ini berdampak pada tingkat kepuasan makan lansia. Selain itu, makanan 
yang dikonsumsi lansia setiap harinya beragam.

Pada umumnya lansia mengalami penurunan fisik. Walaupun lansia mengalami penurunan fisik namun pihak panti tetap memperhatikan kondisi lansia yang selanjutnya pihak panti akan mengatur makan lansia sehingga makanan yang disediakan disesuaikan dengan kondisi tubuh lansia. Hal tersebut memberikan dampak baik bagi kepuasan makan.

Hampir sebagian besar lansia dan didukung oleh hasil penelitian menunjukan presentasi kepuasan makan lansia tinggi. Selain karena rasa, tekstur, tampilan, variasi dan porsi makanan, tingginya persentase kepuasan makan juga dikarenakan sebagian besar lansia menganggap makanan sebagai hal positif dalam hidupnya dan lansia senang dengan makanan yang mereka makan. Lansia juga senang dengan pelayanan makan dari pihak panti, makanan yang lansia makan memberikan kepuasan bagi kehidupan lansia dalam hal ini makanan membuat kondisi hidup mereka lebih baik, serta lansia bebas mengambil makanan sesuai dengan porsi yang diinginkan. Berkaitan dengan porsi, kepuasan yang lansia alami juga dikarenakan tidak adanya sisa makanan.

\section{Hubungan kualitas hidup dan food satisfaction}

Sebagian besar responden pada penelitian ini berada pada rentang umur 7590 tahun. Pada usia ini umumnya akan terjadi perubahan pada fisik maupun psikologis. Kondisi fisik yang semakin renta membuat lansia membatasi aktivitas fisik. Oleh karena itu pihak panti memiliki program senam bagi lansia untuk membantu lansia tetap menjaga kebugaran. Selain dengan senam, pemenuhan makan lansia juga pihak panti perhatikan. Lansia akan mudah lelah, stres, bahkan sakit dikarenakan faktor umur dan hal tersebut mempengaruhi makan lansia. Saat lansia dalam kondisi seperti itu lansia tidak ingin memakan makanannya karena lidah yang terasa pahit maka ada dorongan untuk tidak makan. Hal tersebut dikarenakan kemampuan jaringan pada indra pengecap untuk mengganti dan mempertahankan fungsi normalnya sudah mulai berkurang. Hal ini diperjelas oleh penelitian Sunariani (2009) yang menjelaskan bahwa penurunan nafsu makan terjadi pada tingkat perifer/reseptor indera rasa pengecap pada taste buds. Perubahan predominan rasa pahit dapat menurunkan nafsu makan. Walaupun lansia dalam kondisi tersebut, pihak panti berusaha menyediakan makanan yang dapat membangkitkan selera makan lansia agar lansia tetap bisa makan dan merasa puas dengan makanannya.

Kondisi lingkungan panti yang aman dan nyaman menyebabkan lansia merasa tenang. Ketenangan yang dirasakan lansia ini secara tidak langsung membuat kondisi psikologisnya menjadi baik dan hal tersebut membuat lansia hidupnya menjadi baik. Hal positif inilah yang menyebabkan lansia memberikan respon baik terhadap pelayanan yang disediakan terutama makanan sehingga lansia akan merasa puas dengan makanan yang diperoleh.

Menurut Kuntjoro dalam Hayulita (2018), untuk meningkatkan kualitas hidup lansia dipengaruhi oleh beberapa faktor yang menyebabkan seorang lansia untuk tetap bisa berguna di masa tuanya, yakni kemampuan menyesuaikan diri dan menerima segala perubahan dan kemunduran yang dialami serta adanya penghargaan dan perlakuan yang wajar dari lingkungan para lansia. Kondisi lingkungan erat kaitannya dengan psikologis. Saat kondisi lingkungan baik dan nyaman akan membuat kondisi psikologis baik, dan hal tersebut akan membuat suasana hati juga baik. Pada saat lingkungan baik dan didukung oleh suasana hati yang baik maka napsu makan lansia baik sehingga tingkat kepuasan makannya juga meningkat.

\section{SimpUlan DAN SARAN}

Berdasarkan hasil penelitian menunjukan adanya hubungan signifikan antara kualitas hidup dengan food satisfaction, semakin baik kualitas hidup lansia maka semakin tinggi food satisfaction.

Pada penelitian ini berfokus pada satu panti saja sementara untuk untuk menggali tentang kualitas hidup dan food satisfaction lansia akan memberikan informasi beragam apabila kriteria responden diperluas seperti, lansia yang tinggal dengan anak, maupun 
lansia yang tinggal di rumah sendiri/bersama pasangan. Sehingga untuk penggembangan penelitian ini disarankan agar dapat memperluas kriteria responden dan melakukan mixed method terhadap kualitas hidup lansia dan food satisfaction lansia di PTSW Ina Kaka Provinsi Maluku.

\section{DAFTAR PUSTAKA}

[1] Amarantos, E., Martinez, A., \& Dwyer, J. (2001). Nutrition and quality of life in older adults. The Journals of Gerontology series A: Biological sciences and Medical sciences, 56(suppl_2), 54-64.

[2] Aliabadi, M., Kimiagar, M., GhayourMobarhan, M., Shaker, M. T., Nematy, M., Ilaty, A. A., ... \& Lanham-New, S. (2008). Prevalence of malnutrition in free living elderly people in Iran: a cross-sectional study. Asia Pacific journal of clinical nutrition, 17(2), 285289.

[3] Azizah, R., \& Dwi Hartanti, R. (2016). Hubungan antara tingkat stress dengan kualitas hidup lansia hipertensi di wilayah kerja puskesmas wonopringgo pekalongan.

[4] Statistik, B. P. (2019). Statistik Penduduk Lanjut Usia Tahun 2019. Jakarta: BPS.

[5] Gureje, O., Kola, L., Afolabi, E., \& Olley, B. O. (2008). Determinants of quality of life of elderly Nigerians: results from the Ibadan study of ageing. African journal of medicine and medical sciences, 37(3), 239.
[6] Hayulita, S., Putra, A. B. Y., \& Sari, A. N. (2018). Faktor dominan yang berhubungan dengan kualitas hidup lansia. 'AFIYAH, 5(2).

[7] Nugroho, W. (2008). Keperawatan gerontik \& geriatrik edisi 3. Jakarta: Egc.

[8] Noorkasiani, S. T. (2009). Kesehatan usia lanjut dengan pendekatan asuhan keperawatan. Jakarta: Salemba Medika.

[9] Risdianto, R. (2009). Hubungan Dukungan Sosial Dengan Kualitas Hidup Lanjut Usia Di Desa Kembang Kuning Cepogo Boyolali (Doctoral dissertation, Universitas Muhammadiyah Surakarta).

[10] Rosita., (2012). Stressor Sosial Biologi Lansia Panti Werdha Usia dan Lansia Tinggal Bersama Keluarga. Jurnal BioKultur, I(1).

[11] Rohmah, A. I. N., \& Bariyah, K. (2012). Kualitas hidup lanjut usia. Jurnal Keperawatan, 3(2).

[12] Sunariani, J. (2009). Perubahan Konsentrasi Il-1 Dan Gustducin Terhadap Rasa Pengecap Pahit Pada Demam. J. Penelit. Med. Eksakta, 8(3).

[13] Suprajitno, S. (2019). Asuhan Keperawatan Keluarga: Aplikasi Dalam Praktik (67).

[14] Yuliati, A., Baroya, N.M. and Ririanty, M., 2014. Perbedaan kualitas hidup lansia yang tinggal di komunitas dengan di pelayanan sosial lanjut usia (The different of quality of life among the elderly who living at community and social services). Pustaka Kesehatan, 2(1). 